\title{
IS THE PREVALENCE OF CELIAC DISEASE INCREASED AMONG EPILEPTIC PATIENTS?
}

\author{
Riccardo Pratesi', Lenora Gandolfi', Rita C. Martins' ${ }^{2}$, Pedro L. Tauil', \\ Yanna Karla Nobrega ${ }^{3}$, Wagner Afonso Teixeira ${ }^{4}$
}

\begin{abstract}
Objective: To assess the prevalence of celiac disease (CD) among a group of epileptic patients attending the Epilepsy Clinics of two general hospitals in the city of Brasilia (DF), Brazil. Method: Serum samples were collected from 255 epileptic patients (119 children, 136 adults) originating from Epilepsy Clinics, and from a control group composed by 4405 individuals ( 2034 children, 2371 adults) attending the Laboratory of Clinical Analysis, for routine blood testing. The diagnosis of CD was determined by the antiendomysium antibody (IgA-EMA) test and by small intestine biopsy. Results: two of the 255 epileptic patients (1:127) and fifteen subjects from the control group (1:293) tested positive for the IgA-EMA assay. Conclusion: the prevalence of CD was 2.3 times higher in epileptic patients than in controls (7.84 per 1000 versus 3.41 per 1000). Although still not statistically significant, this result is highly suggestive of an increased prevalence of CD among epileptic patients.
\end{abstract}

KEY WORDS: celiac disease, gluten-sensitive enteropathy, epilepsy, prevalence

\section{A prevalência da doença celíaca é elevada entre pacientes com epilepsia?}

RESUMO - Objetivo: Determinar a prevalência da doença celíaca (DC) num grupo de pacientes epilépticos atendidos em ambulatórios de especialidade de dois hospitais gerais na cidade de Brasília (DF). Método: Amostras de soro foram colhidas de 255 pacientes epilépticos (119 crianças, 136 adultos) e de uma população formada por 4405 indivíduos (2034 crianças, 2371 adultos), atendidos no Laboratório de Análises Clínicas para exames de rotina. 0 diagnóstico de DC foi estabelecido por meio do teste de anticorpos antiendomísio (IgA-EMA) e por biópsia do intestino delgado. Resultados: dois dos 255 pacientes epilépticos (1:127) e quinze indivíduos do grupo controle (1:293) apresentaram biópsia compatível e resultados positivos no teste lgAEMA. Conclusão: a prevalência de DC foi 2.3 vezes maior em pacientes epilépticos do que nos controles (7.84 per 1000 versus 3.41 per 1000). Apesar deste resultado não ser estatisticamente significativo pode, no entanto ser considerado altamente sugestivo da existência de prevalência aumentada de DC entre pacientes epilépticos.

PALAVRAS-CHAVE: doença celíaca, enteropatia sensível ao glúten, epilepsia, prevalência.

Celiac disease (CD), also known as gluten-sensitive enteropathy, is a lifelong disorder of variable severity characterized by malabsorption and specific, though not pathognomonic, lesions of the small intestinal mucosa. Mucosal lesions are occasioned by sensitivity to ingested wheat gluten or related barley or rye proteins in genetically susceptible individuals. A strict gluten free diet (GFD) results in regression of the small intestinal abnormalities and a rapid relapse is observed on reintroduction of dietary gluten. The importance of genetic factors in the emergence of $\mathrm{CD}$ is evidenced by the finding of an increased prevalence of the disease among first degree relatives ${ }^{1}$ and by a concordance of approximately 75 percent among homozygous twins ${ }^{2}$. CD is strongly associated with HLA class II antigens and over 95 percent of CD patients express the HLA-DQ $(\alpha 1 * 0501, \beta 1 * 0201)$ heterodimer. Nonetheless only a minority of $\mathrm{DQ} 2$ positive subjects will develop the disorder since the overall importance of non-HLA still unidentified genes is considered greater than that of HLA genes ${ }^{3}$. The pathogenesis of $C D$ is still not completely understood but several lines of evidence point to a probable autoimmune mechanism, triggered by an inappropriate T-cell-mediated immune response against dietary gluten. The enzyme tissue transglutaminase (tTG) is the prominent, if not sole, target of the autoimmune response ${ }^{4}$.

\footnotetext{
${ }^{1}$ Medicina da Criança e do Adolescente e Medicina Social, Faculdade de Medicina da Universidade de Brasília, Brasília DF, Brasil (UNB): Professor Adjunto. Laboratório de Análises Clínicas, Hospital Universitário UNB; ${ }^{2}$ Bióloga e pós-graduanda; ${ }^{3}$ Farmacêutica-bioquímica ${ }^{4}$. Unidade de Neurologia; ${ }^{4}$ Hospital de Base de Brasília, Chefe do Setor de Epilepsia.
}

Received 29 November 2002. Accepted 31 January 2003. 
Although, by definition $C D$ is considered a disease of the gastrointestinal tract and, indeed, the finding of an abnormal jejunal mucosa is essential for the diagnosis, its clinical manifestations can be extremely variable. Typical forms, usually seen in childhood, are mainly characterized by chronic diarrhea, bloating, muscle wasting and impaired growth. In atypical forms, generally seen in older children or in adults, gastrointestinal complaints are less prominent and extra-intestinal manifestations (e.g., short stature, osteoporosis, delayed menarca, iron deficient anemia) usually predominate. Silent forms, in which a typical gluten-sensitive enteropathy is found in apparently asymptomatic subjects, can also be eventually detected. A more accurate anamnesis usually shows that many of these silent cases are affected by minor complaints associated with a decreased psychosocial well- being. $C D$ is a life-long disorder and its only effective treatment is a life-long GFD. To maintain a diet that will last through life is a difficult task, particularly in childhood and adolescence. Therefore, it is extremely important to obtain a precise diagnosis before starting the GFD. The first criteria for the diagnosis of $C D$, established by the European Society of Pediatric Gastroenterology and Nutrition (ESPGAN) in $1970^{5}$ were based on the results of three sequential jejunal biopsies. During the last two decade, with the advent of reliable serological assays to detect the disease activity, the diagnosis of $C D$ was greatly facilitated. Given the high sensitivity and specificity reported for these screening tools, especially for the antiendomysium (IgA-EMA $)^{6}$ and antitransglutaminase antibody test (IgA-tTG) ${ }^{7}$, it is now accepted a definitive diagnosis of CD based on positive serological results and a single intestinal biopsy showing a flat or severely damaged mucosa, followed by a favorable clinical and serological response to gluten free diet (GFD) ${ }^{8}$. Serological assays, besides helping in the diagnostic process, also made possible an active search for new cases. The screening of the general population using serological tests demonstrated that $C D$ is one of the commonest life-long disorders. Nonetheless, there is a still prevalent lack of awareness by health providers that frequently results in delayed diagnosis. It has been shown that the period of time between the onset of the first symptoms and the final diagnosis can vary from 2 to more than 5 years 9 . In a recent European study, the ratio between clinically diagnosed and undiagnosed cases of $C D$, the latter found by mass screening, was 1 to $7^{10}$.

$C D$ has been reported in association with various diseases with known autoimmune basis, such as der- matitis herpetiformis, type I diabetes, rheumatoid arthritis, thyroiditis, and Sjogren's syndrome ${ }^{4}$. Genetic disorders known for their association to other autoimmune diseases, as Down syndrome ${ }^{11}$, and Turner syndrome ${ }^{12}$, also show a high CD prevalence. During the last decades it has become increasingly evident that celiac patients can also manifest a variety of disorders of the central and peripheral nervous system. Neurological disorders described in association with $C D$ include, among others, sporadic and progressive cerebellar ataxia, cerebral atrophy and dementia, cerebral vasculitis, myopathy, peripheral neuropathy and epilepsy ${ }^{13}$. During the last few decades, several screening studies on the prevalence of $C D$ among epileptic patients ${ }^{14-16}$ were published, and the existence of a syndrome, initially described by Gobbi et al. ${ }^{17}$, characterized by the association of $C D$, epilepsy and occipital calcifications is, by now, well established and confirmed by several later series $^{18,19}$ and case reports ${ }^{20,21}$. Apparently the prevalence of CD among epileptic patients is increased although a chance association between epilepsy and $C D$ can not be excluded, since the prevalence of asymptomatic $C D$ in the general population, as previously cited, appears to be relatively high. The causes of the various neurological dysfunctions, including epilepsy, seen in association with $C D$ are poorly understood. Autoimmune mechanisms have been considered a possible cause. The finding of other autoantibodies in cases of refractory epilepsies as e.g. glutamic acid decarboxylase (GAD) auto-antibodies $^{22}$, glutamate receptor (GluR3) antibodies ${ }^{23}$, and anti-GM1 antibodies ${ }^{24}$ in some patients with refractory or localization related epilepsies reinforces the notion that epilepsy may, at times, be due to autoimmune mechanisms.

This study was undertaken to assess the prevalence of $C D$ among adults and children with epilepsy attending the Seizure Clinics of two general hospitals of the city of Brasilia (DF), Brazil.

\section{METHOD}

Between November 1998 and March 2002 serum samples were collected from adults attending the Epilepsy Clinic of the Hospital de Base de Brasilia, and children attending the Pediatric Seizure Clinic of the Hospital Universitario de Brasilia. Samples were stored at $-80^{\circ} \mathrm{C}$ until testing. The study design was approved by the Ethics Committee of the University of Brasilia School of Health Sciences and all adult participants or, in case of children, their parents, received written and verbal information regarding the objectives of the screening and gave informed consent. Seizures were classified according to the scheme of the International League against Epilepsy ${ }^{25}$. The etiology was 
not considered an excluding factor being admitted to the study patients with idiopathic, symptomatic, and cryptogenic epilepsy. All patients admitted to the study had suffered at least two unprovoked seizures. A population composed by 4405 individuals (respectively, 2034 children, and 2371 adults), attending the Laboratory of Clinical Analysis of the Brasilia University Hospital for routine blood tests, was considered as control group. These patients were

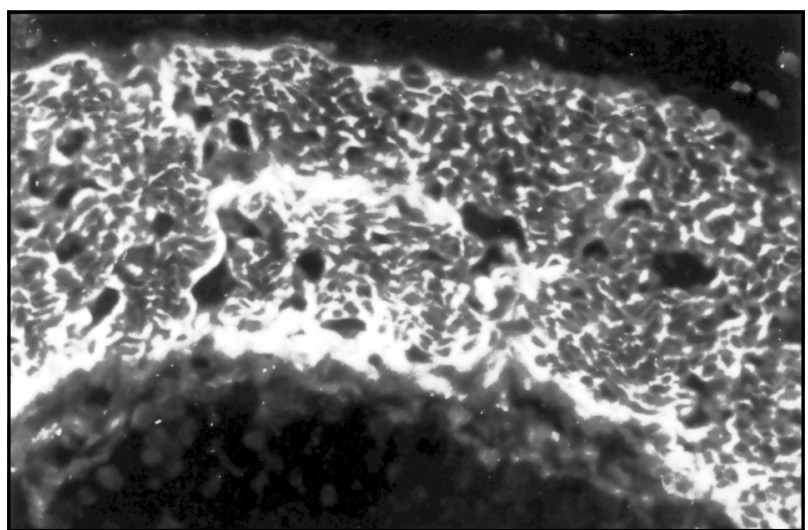

Fig 1. Adult patient's positive immunofluorecence test, showing characteristic honeycomb-like brilliant pattern of primate (Cebus apella) esophagus smooth muscle bundles (magnification $\times 400$ ). The child's test displayed a similar pattern.

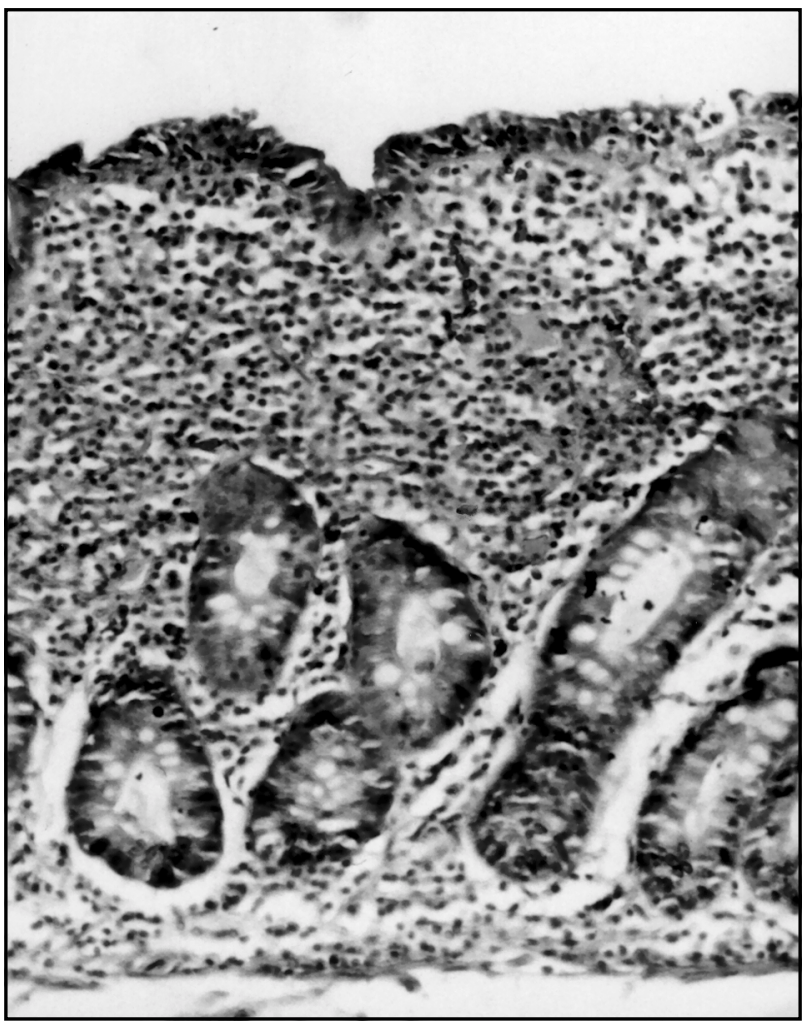

Fig 2. The child's intestinal biopsy specimen showing total villous atrophy (flat mucosa) with crypt hypertrophy and increased number of intraepithelial lymphocytes. part of an ongoing screening program for $C D$ and, in order to avoid selection bias, subjects with blood test requisitions originating from pediatric or adult Gastroenterology Clinics were excluded. The most frequent reasons for blood testing were routine health check-up, suspected or recurrent infection, chronic ailments, metabolic diseases or pre-operative check-up. No inquire was performed among control group subjects about the possible presence of epilepsy, and this can be considered a minor bias. However, no cases of epilepsy were detected among the 15 control group $C D$ positive patients. Both, patients and controls, were screened for celiac disease applying the antiendomysial antibodies test (IgA-EMA), according to standard immunofluorescence technique using fixed cryostat sections from the distal portion of primate esophagus (Cebus apella) as antigen substrate ${ }^{6}$. Fluorescein-labeled goat antibody to human IgA was used as second antibody. All sera were screened at a dilution of $1 / 5$. Under the fluorescence microscope the presence of a characteristic brilliant green network pattern was taken as positive (Fig. 1). To confirm the diagnosis of $C D$ jejunal biopsy (children under three years) or duodenal biopsy (older children and adults) were suggested to IgA-EMA positive patients. Jejunal biopsies were performed with a Watson pediatric capsule and samples were taken at the ligament of Treitz. The duodenal biopsies were performed using an Olympus WM-30 videogastroscope (Olympus Keymed, UK), two to three samples being taken, under direct visualization, from the second portion of the duodenum.

\section{RESULTS}

Serum samples were obtained from 119 children (49 girls and 70 boys, age range one to 14 years, mean 7.97, median 8) and from 136 adults ( 72 men and 64 women, age range 15 to 65 , mean 30.27 , median 29). Of the total group of 255 epileptic patients, two patients disclosed a positive IgA-EMA test (1:127). The control group was composed by 4405 individuals (2034 children, aged 1-14 years and 2371 adults aged 15-72 years). Eleven children and four adults tested positive for the IgA-EMA assay. The overall prevalence of the control group was 1:293.

The two positive epileptic patients were a 33-yearold woman and a 3-year-six-month-old boy. Jejunal biopsy, performed in both patients, revealed the typical aspect of celiac enteropathy (complete villous atrophy with hypertrophic criptae and increased number of intraepithelial lymphocytes) (Fig. 2). Both celiac patients had history of difficult to control seizures. The adult patient had a long lasting history of complex partial seizures, starting when she was 15years-old. She had taken in the past, several different antiepileptic drugs (AED) but her seizures never had been completely controlled. Her CT scan revealed significant mesial temporal sclerosis on the left 
hemisphere. She was on high dose of carbamazepine $(65 \mathrm{mg} / \mathrm{kg} /$ day), but still having several seizures, almost every week. In spite of the high dose of AED and a good compliance with the medication, her blood levels were consistently on the low therapeutic range arising the suspicion of malabsorption. She was underweight, and complained of depression, poor disposition and a chronic lack of appetite but did not disclose any symptoms related to the gastrointestinal tract.

The child, that never had previously suffered any seizure and had a negative family history for epilepsy, was admitted to the hospital emergency room due to a first generalized tonic-clonic seizure, that progressed, days later, to frequent short lasting complex partial seizures and by brief and frequent (more than fifty times a day) atonic attacks. Tonic-clonic seizures also continued to recur sporadically, mainly during sleep. Both physical and neurological examination were normal aside a moderate degree of unsteadiness and attention deficit. His electroencephalogram was suggestive of Lennox-Gastaut syndrome, disclosing a slow background intermixed by frequent sharp-and-slow-wave complexes. The remaining diagnostic work-up, which included CT-scan, MRI, screening for inborn errors of metabolism and determination of CSF IgG index and electrophoresis for presence of oligoclonal bands was completely normal.

\section{DISCUSSION}

More than three decades have elapsed since the first descriptions of neurological dysfunction and epilepsy in patients suffering celiac disease ${ }^{26}$ but the mechanisms involved in the sudden emergence and progression of the various disorders of the central and peripheral nervous system are still elusive. Studies on the possible association between celiac disease and epilepsy are scarce. Some of the studies have shown an increased prevalence of epilepsy among celiac patients 27,28 . Some, inversely, have shown increased prevalence of $C D$ among epileptic patients ${ }^{14,15}$, while others failed to show any difference ${ }^{29}$. In this study, the prevalence of CD was 2.3 times higher in patients with epilepsy than in controls (7.84 per 1000 in patients with epilepsy versus 3.41 per 1000 in controls), Although these results could be considered suggestive of an increased prevalence of $C D$ among patients with epilepsy, applying the Fisher exact test to determine the statistical significance of the difference between the two groups the conclusion is that the difference is still not statistically significant [prevalence ratio $=2.3 ; \mathrm{Cl}=95 \%(0.53-$
10.02); $p$-value $=0.23$ ]. Perhaps an increase in the sample size, possibly through a multicenter study, may confirm the existence of a higher and statistically significant prevalence of CD among epileptic patients.

Taking our findings into account and reviewing previously published studies, some general observations concerning the association between epilepsy and $C D$ can be brought forward: (a) in many epileptic patients $C D$ is asymptomatic or disclose only mild or atypical features ${ }^{14,15}$; (b) epilepsy without cerebral calcifications, may be an early manifestation of CD, with calcifications developing later ${ }^{30}$; (c) early identification and treatment of $C D$ may reverse the tendency to epilepsy and probably to the development of calcifications ${ }^{16}$; (d) seizures seen in association with $C D$ are frequently difficult to control and, at least in some cases, this is due to poor AEDs absorption resulting from the concurrent enteropathy ${ }^{17}$; (e) if CD is not precociously diagnosed, epilepsy will have propensity to progress in severity, evolving to a degree in which, even the introduction of GFD will fail to ameliorate the clinical picture ${ }^{17}$; (f) although generalized forms of epilepsy are seen that, at times, rapidly evolve to a severe and progressive encephalopathy suggestive of Lennox-Gastaut syndrome ${ }^{31}$, partial complex seizures with involvement of the occipital lobes are more frequent ${ }^{16}$.

In conclusion, a greater attention is needed to the possible coexistence of CD in epileptic patients. Although a systematic screening for CD in all epileptic patients seems to be, at the present time, neither practical nor cost-effective, it seems reasonable to screen at least all patients with complex partial seizures, especially when associated with occipital paroxysms and resistance to drug therapy.

\section{REFERENCES}

1. Littlewood JM. Coeliac disease in childhood. Baillieres Clin Gastroenterol 1995;9:295-327.

2. Shale DJ, Johnston DG, Hall R, Roberts DF. Coeliac disease in monozygotic twins. Postgrad Med J 1982;58:797-798.

3. Sollid LM, Thorsby E. HLA susceptibility genes in celiac disease: genetic mapping and role in pathogenesis. Gastroenterology 1993;105:910-922.

4. Farrell R, Kelly CP. Current concepts: celiac sprue. N Engl J med 2002;346:180-188.

5. Meeuwisse GW. Diagnostic criteria in celiac disease. Acta Paediatr Scand 1970;59:461-463.

6. Chorzelski TP, Beutner EH, Sulej J, et al. IgA antiendomysium-antibody. A new immunological marker of dermatitis herpetiformis and coeliac disease. Br J Dermatol 1986;87:703-706.

7. Biagi F, Ellis HJ, Yiannakou JY, et al. Tissue transglutaminase antibodies in celiac disease. Am J Gastroenterol 1999;94:2187-2192.

8. Working Group of European Society of Paediatric Gastroenterology and Nutrition. Revised criteria for diagnosis of celiac disease. Arch Dis Child 1990;65:909-911.

9. Lankish PG, Martinez Schramm A, Petersen F, Dröge M, Lehnick D, Lembcke B. Diagnostic intervals for recognizing celiac disease. $Z$ Gastroenterol 1996;34:473-477. 
10. Catassi C, Fabiani E, Ratsch IM, et al. The coeliac iceberg in Italy. A multicentre antigliadin antibodies screening for coeliac disease in school-age subjects. Acta Paediatr Suppl 1996:412:29-35.

11. Carlsson A, Axelsson I, Borulf S, et al. Prevalence of IgA-antiglidin antibodies and IgA-antiendomysium antibodies related to celiac disease in children with Down syndrome. Pediatrics 1998;101:272-275.

12. Ivarsson S-A, Carlsson A, Bredberg A, et al. Prevalence of coelic disease in Turner syndrome. Acta Paediatr 1999;88:933-936.

13. Muller AF, Donelly MT, Smith CML, Grundman MJ, Holmes GKT, Toghill PJ. Neurological complications of celiac disease: a rare but continuing problem. Am J Gastroenterol 1996;91:1430-1435.

14. Fois A, Vascotto M, Di Bartolo RM, Di Marco V. Celiac disease and epilepsy in pediatric patients. Childs Nerv Syst 1994;10:450-454.

15. Cronin CC, Jackson LM, Feighery C, et al. Coeliac disease and epilepsy. Q J Med 1998;91:303-308.

16. Labate A, Gambardella A, Messina D, et al. Silent celiac disease in patients with childhood localization-related epilepsies. Epilepsia 2001;42:1153-1155.

17. Gobbi G, Bouquet F, Greco L, et al. Coeliac disease, epilepsy, and cerebral calcifications. Lancet 1992;340:439-443.

18. Ambrosetto G, Antonini L, Tassinari CA. Occipital lobe seizures related to clinically asymptomatic celiac disease in adulthood. Epilepsia 1992;33:476-481.

19. Magaudda A, Dalla Bernardina B, De Marco P, et al. Bilateral occipital calcification, epilepsy and coeliac disease: clinical and neuroimaging features of a new syndrome. J Neurol Neurosurg Psychiatry 1993; $56: 885-889$

20. Bye AM, Andermann F, Robitaille $Y$, Oliver M, Bohane T, Andermann E. Cortical vascular abnormalities in the syndrome of celiac disease, epilepsy, bilateral occipital calcifications, and folate deficiency. Ann Neurol 1993;34:399-403.
21. Souza Santos CH, Brandão de Almeida IL, Costa Gomes MD, et al. Calcificação intracraniana occipital bilateral, epilepsia e doença celíaca. Arq Neuropsiquiatr 2002;60:840-843.

22. Peltola J, Kulmala P, Isojarvi J, et al. Autoantibodies to glutamic acid decarboxylase in patients with therapy-resistant epilepsy. Neurology 2000;55:46-50.

23. Wiendl H, Bien CG, Bernasconi P, et al. GluR3 antibodies: prevalence in focal epilepsy but no specificity for Rasmussen's encephalitis. Neurology 2001;57:1511-1514.

24. Bartolomei F, Boucraut J, Barrie M, et al. Cryptogenic partial epilepsies with anti-GM1 antibodies: a new form of immune-mediated epilepsy? Epilepsia 1996;37:922-926.

25. Commission on Classification and Terminology of the International League Against Epilepsy: proposal for revised classification of epilepsy and epileptic syndromes. Epilepsia 1989;30:389-399.

26. Cook WT, Smith WT. Neurological disorders associated with adult coeliac disease. Brain 1966;89:683-722.

27. Chapman RWG, Laidlow JM, Colin-Jones D, Eade OE, Smith CL. Increased prevalence of epilepsy in coeliac disease. Br Med J 1978;22:250-251.

28. Holmes GKT. Non-malignant complications of coeliac disease. Acta Paediatr 1996;412 (Suppl):68-75.

29. Hanly JG, Stassen W, Whelton M, Callaghan N. Epilepsy and coeliac disease. J Neurol Neurosurg Psychiatry 1982;45:729-730.

30. Ambrosetto G, Antonini L, Tassinari CA. Occipital lobe seizures related to clinically asymptomatic celiac disease in adulthood. Epilepsia 1992;33:476-481.

31. Bernasconi A, Bernasconi N, Andermann F, et al. Celiac disease, bilateral occipital calcifications and intractable epilepsy: mechanisms of seizures origin. Epilepsia 1998;39:300-306. 